\title{
The Effect of Nasogastric Tube Feeding Educational Interventions on Critical Care Nurses' Knowledge and Performance
}

\author{
Inayat F.Elsayed*1, Amal R. Reyad2, Hala A. Abdelrahman3, \\ Marwa M. Mahmoud4, Nahed A. Kandeel5 \\ *1 Nurse Specialist, Mansoura University Students' Hospital \\ e-mail Marianelmenawy@yahoo.com \\ 2 Professor of Anaesthesia and Intensive Care, Faculty of Medicine, Mansoura University \\ 3, 4 Lecturer, Critical Care and Emergency Nursing, Faculty of Nursing, Mansoura University \\ hawk_hawk3@yahoo.com halaabdelrahma@yahoo.com \\ 5 Professor of Critical Care and Emergency Nursing, Faculty of Nursing, Mansoura \\ University,Egypt Nahed Kandeel2000@yahoo.com
}

\begin{abstract}
Background: Critically ill patients have complex nutritional needs to meet the metabolic response to critical illness. The nutritional support for critically ill patients is an important determinant of their survival and recovery. Critical care nurses are the primary ones responsible for feeding the patients in intensive care units. Therefore, their knowledge and performance are important for providing adequate nutritional support for their patients and prevent malnutrition complications. Aim: The current study aimed to assess the effect of nasogastric tube feeding educational interventions on critical care nurses' knowledge and performance. Method: A quasi-experimental one-group with pre and post-test design was used with a convenience sample of 60 critical care nurses working in four intensive care units affiliated with a university hospital in Egypt. The data were collected by using two tools: 'nasogastric tube feeding knowledge questionnaire' and 'nasogastric tube feeding observation checklist'. Results: Statistically significant differences were noted in the total mean scores of nurses' knowledge and performance of nasogastric tube feeding before and after the educational interventions. Improvement of participant nurses' knowledge and performance was markedly noted one month after education, however, a decline in knowledge and performance was evident after three months. Conclusion and Recommendations: Educational interventions can improve nurses' knowledge and performance of nasogastric tube feeding, and this will be positively reflected on patients' outcomes. Therefore, we recommend organizing continuous educational activities for critical care nurses to keep them up-to-date and competent.

Keywords: Nasogastric Tube Feeding, Educational Interventions, Critical Care Nurses, Knowledge, Performance.
\end{abstract}


Inayat F.Elsayed*1, Amal R. Reyad2et. al.

Introduction
Critical illness is a life-threatening condition that can lead to significant morbidity or mortality (Bennett, Robertsoon \& Al-Haddad, 2016). It is usually associated with a hypermetabolic state related to the stimulation of many catabolic hormones (Ndahimana \& Kim, 2018). This can contribute to changes in energy expenditure, increase in blood glucose level, a decline in muscle function, and psychological and behavioral disorders (Preiser, Ichai, Orban \& Groeneveld 2014). Hence, critically ill patients have complex nutritional needs to meet the metabolic response to critical illness and are at high risk for malnutrition (McClave, Martindale, Rice \& Heyland, 2014). The optimal nutritional support for critically ill patients is an important determinant of their survival of critical illness and recovery (Bear et al., 2017; Ndahimana \& Kim, 2018).

It has been reported that the prevalence of malnutrition on hospital admission was $31 \%$ and before discharge was 36\% (van Vliet, Gomes-Neto, de Jong, Jager-Wittenaar \& Navis, 2020). Additionally, Kirkland, Kashiwagi, Brantley, Scheurer, and Varkey (2013), estimated that nearly $50 \%$ of patients are malnourished on admission and other patients develop malnutrition during hospitalization. In the intensive care unit (ICU), despite the nasogastric tube (NGT) feeding is a common practice, many patients remain undernourished or malnourished which is associated with poor clinical outcome (Marshall \& West, 2006; Stewart, 2014). A prospective study conducted by Kim and Choi-Kwon (2011) on enteral feeding (EF) in the ICU reported that $75 \%$ of the patients were severely malnourished at admission and the nutritional status worsened markedly during the ICU stay.

According to the literature, the critically ill patient may develop malnutrition due to the nature of the critical illness, hypermetabolic states, and stressors of the ICU (Shahin, Mohamed, \& Sayed, 2012). Malnutrition is a clinical condition that affects multiple patient groups and can have a significant impact on clinical outcomes (Barker, Gout \& Crowe, 2011; Stewart, 2014). It is usually associated with many complications such as infection, pressure ulcers, impaired wound healing (Kim, Stotts, Froelicher, Engler, \& Porter 2012), disease severity, high morbidity and mortality, longer hospital stays, and increased health care costs (Correia \& Waitzberg, 2003; Kim et al., 2012).

Enteral feeding is a useful and well-tolerated approach for patients with normal gastrointestinal function but unable to ingest adequate nutrients through the oral route (Ojo Keaveney, Wang \& Feng, 2019). It is more preferable to other feeding methods in the ICU as it enhances patients' immunity and survival, and is less expensive (Das, Patra, \& Pradhan, 2015). The NGT is commonly used for critically ill patients for feeding and gastric decompression (Williams \& Leslie 2004). Critical care nurses have a significant role in the delivery and management of EF and maintaining patient's optimal nutritional status (Das, et al., 2015; Morphet, Clarke \& Bloomer, 2016). They are accountable for NGT insertion, ensuring its appropriate placement, giving the feeding, and monitoring its associated complications (Xu, Huang, Lin, Zheng, \& Zhu, 2020). They can also identify susceptible 
patients for malnutrition, assess nutritional adequacy, and implement nursing interventions to prevent and manage malnutrition (Sauer, Alish, Strausbaugh, West \& Quatrara, 2016; Stewart, 2014).

Some studies investigated nurses' knowledge and/or practice related to EF of critically ill patients and reported marked variability. A recent study conducted by Kunwar and Koirala (2019) found that more than half of the nurses had an unsatisfactory level of knowledge and practice concerning NGT feeding. Das et al. (2015) found that 44\% of the nurses had above-average knowledge about EF for critically ill patients and $44 \%$ had below-average knowledge. Mula, Ncama, and Maluwa (2014) reported variations in nurses' knowledge that ranged from adequate knowledge in many aspects of care to lacked knowledge in some other aspects. Marshall and West (2006) conducted a survey study to investigate the EF practices of 376 critical care nurses and reported a greater discrepancy in nurses' practice which may lead to underfeeding of critically ill patients. In her Doctoral study, Marshall (2008) found that nurses depend greatly on the verbal testimony of others for their clinical practice rather than access to guidelines and evidencebased practice which may cause inconsistency in their knowledge and clinical practice. She highlighted the need for developing strategies for promoting the transfer of knowledge into clinical practice and integrating such strategies into undergraduate nursing education.

Since critical care nurses are responsible for the delivery and management of NGT feeding in the ICU, their knowledge and practice concerning this procedure are important to accomplish these tasks safely and competently (Gill, 2019). Yet, nursing interventions related to NGT feeding is based upon nurses' own judgment rather than the best available evidence (Williams \& Leslie 2004). Few studies were conducted in Egypt to address nurses' knowledge and/or practice concerning NGT feeding. These studies reported inadequate nurses' knowledge and incompetent practice (Abdullah, Mohammed, Ismail, 2014; Bedier, ELAta, Shehab, 2016; Metwaly, E. Mohammed, Mohammed, 2013; Mohammed, Mahmoud, Sleem \& Shehab, 2017; Shahin, et al., 2012). These findings highlighted the need for enhancing nurses' knowledge and practice to ensure optimal nutritional support for critically ill patients. Hence, this study was carried out to address this issue.

\section{Aim of the study}

This study aimed to assess the effect of NGT feeding educational interventions on critical care nurses' knowledge and performance.

\section{Research hypothesis}

To fulfill the aim of the study, we hypothesized that critical care nurses' knowledge and performance mean scores will be improved after the implementation of NGT feeding educational interventions compared to their mean scores pre-interventions.

\section{Method
Research Design}

This study has a quasiexperimental, one group, pretest-posttest design. This type of design is mainly used to estimate the effect of an intervention on some outcomes without randomization (Polit, \& Beck, 2018).

Setting

This study was conducted in four ICUs affiliated with a university hospital 
in Egypt including Neurological ICU (5 beds), Cardiothoracic ICU (4 beds), Neurosurgery ICU ( 5 beds), and Surgical ICU ( 9 beds). These units are well prepared with the technology required for the management of critically ill patients. The nurse-patient ratio in the selected units is nearly $1: 2$ in morning shifts and 1:3 in afternoon shifts.

Subjects

The study involved a convenience sample of critical care nurses (60 nurses) working in the above-mentioned ICUs who had at least one year of work experience in the study setting, were involved in providing patient care and accepted to take part in this investigation. Data Collection Tools two tools:

The data were collected by using

Tool I: Nasogastric Tube Feeding Knowledge Questionnaire for Critical

\section{Care Nurses}

This tool was developed by the principal investigator (PI) after reviewing relevant literature. It aimed to assess critical care nurses' knowledge regarding NGT feeding pre and post the educational sessions. It compromises of two parts:

\section{Part 1: Critical Care Nurses' Demographic Characteristics}

This part covered the demographic characteristics of the participant nurses including age, gender, marital status, educational level, years of work experience, and attended previous training programs regarding NGT feeding.

\section{Part 11: Nasogastric Tube Feeding} Knowledge Questionnaire

This part was developed based upon relevant literature (AL Kalaldeh, Watson \& Hayter, 2015; Bourgault, Ipe, Weaver, Swartz, O’Dea, 2007; Shahin et al., 2012). It included 30 multiple-choice questions (MCQs) about NGT feeding. It aimed to assess critical care nurses' knowledge about NGT insertion, feeding, and care pre and post the educational intervention. The questionnaire covered 7 areas including general information regarding NGT feeding (4 questions), preparation for NGT insertion (2 questions), NGT insertion (1 question), assessment before feeding (1 question), preparation for feeding ( 2 questions), implementation of feeding (3 questions) and post-feeding care (3 questions).

The correct answer was given one mark and the wrong answer was given a zero. A score of less than $85 \%$ was considered an unsatisfactory level of knowledge while a score of more than $85 \%$ was considered a satisfactory level of knowledge.

Tool II: Nasogastric Tube Feeding Observation Checklist

This tool was developed by the researcher based on relevant literature (Babapour et al., 2016; Bedier, 2016; Shahin et al., 2012) to assess critical care nurses' performance of NGT feeding. Nursing interventions were categorized under five main domains including assessment, preparation, implementation, post-care, and documentation.

In the observation checklist, the interventions were ranked on a threepoint scale from 0 to 2 (done correctly $=$ 2 , done incorrectly $=1$, and not done $=$ $0)$. Also, the total scores were calculated and converted into percent. The scores of less than $85 \%$ were considered an unsatisfactory level of practice, and the scores of more than $85 \%$ were considered a satisfactory level of practice.

Validity and Reliability

The content validity of tools was assessed by a panel of seven experts 
from the fields of Critical Care and Emergency Nursing, the Anesthesia and Intensive Care Medicine. The tools were revised for applicability, relevancy, clarity, and comprehensiveness, and modifications were made accordingly. The knowledge questionnaire was translated into the Arabic language, and the back-translation technique was used to ensure the validity of the translation. The reliability of tools was measured by Cronbach's alpha test and the value was 0.817 for tool I and 0.912 for tool II which reflects reliable tools.

\section{Pilot Study}

A pilot study was carried out on $10 \%$ of the participants before starting the data collection to test the feasibility and applicability of the tools and to make necessary modifications before conducting the main study. This group was not included in the study sample.

\section{Ethical Considerations}

Ethical approval was granted from the local Research Ethics Committee. Informed consent was obtained from the eligible nurses who accepted to participate in the study. They were informed about the details of the study including the aim, educational interventions, the time schedule, and the benefits and risks of participation. They were assured that their participation is voluntary and that they had the right to withdraw from the study at any time without penalty. They were also assured about the confidentiality of their personal information. It was emphasized to them that their knowledge and performance scores would not be included in their annual evaluation.

\section{Data Collection Process}

This study was conducted between January and May 2018. Before commencing the study, permission to carry out this investigation was gained from the authority of the selected university hospital and the ICUs. The PI communicated with the eligible nurses, informed them about the details of the study, and invited them to participate. The questionnaire sheet (pretest) was distributed to all nurses who accepted to take part in the study. Nurses required between 30 and 40 minutes to complete the questionnaire. The PI collected the questionnaire sheets back.

Nurses' performance of the NGT feeding was observed by the PI in the morning shifts. Based on nurses' pretest knowledge and practice scores, areas of inadequate knowledge, and incompetent practice were determined. Then, the PI prepared the NGT feeding educational guide based on the current evidencebased practice. The guide included both theoretical materials and NGT feeding clinical procedures.

Participants were divided into small groups according to their availability in the shift. The educational interventions were arranged during morning shifts from $10 \mathrm{am}-10.45 \mathrm{am}$ at the nurse station in the ICU. Each participant nurse was given a copy of the NGT feeding educational guide. It involved an orientation session and three sessions covered all educational interventions. In the orientation session, the participants were given an overview of the study aim, the procedure, and the sessions' planned schedule. The educational sessions were repeated three times per week for one month to allow the participants to attend the suitable sessions for their work schedule.

In general, each nurse attended three educational sessions. Different teaching methods were used including lectures, discussions, and colored pictures. For the clinical part, a demonstration and re-demonstration of 
Inayat F.Elsayed*1, Amal R. Reyad2et. al.

the procedures were used. The participants were allowed to ask questions and seek clarifications as needed. Nurses' knowledge and performance were evaluated in three phases including pre the educational interventions, and then one month and three months after education.

\section{Statistical Analysis}

Data were analyzed using IBMSPSS software version 25.0. (Armonk, NY: IBM Corp.). Qualitative data were presented as frequencies and percent, and compared using the Chi-square test (Fisher's exact test). Quantitative data were expressed as mean \pm standard deviation (SD). The ANOVA test was utilized to differentiate between repeated measures. Pairwise comparisons were performed to detect significant differences throughout the phases of the study. The test calculates $\mathrm{F}$ value, pvalue, and partial eta square $(\eta 2)$ which is a measure of the effect size. Results were considered statistically significant if $p \leq 0.05$.

\section{Results}

\section{Nurses' Knowledge Regarding NGT} Feeding

Table1 Describes participant nurses'socio-demographic characteristics. It showed that the majority of the nurses $(81.7 \%)$ were aged between $21-30$ years, were females $(85 \%)$ and slightly more than half of them $(53.3 \%)$ were married. Regarding the educational level, $38.3 \%$ had a secondary nursing school certificate and $36.7 \%$ had a Bachelor's Degree in Nursing. The results also illustrated that $40 \%$ of the nurses had more than 10 years of work experience in the ICU and $33.3 \%$ had less than 2 years of work experience in the ICU. Additionally, the vast majority of nurses $(93.3 \%)$ reported that they didn't attend any training programs concerning NGT feeding.

\section{Table 1 Participant Nurses' Socio-demographic Characteristics}

\begin{tabular}{|c|c|c|}
\hline+2 & N (60) & $\%$ \\
\hline \multicolumn{3}{|l|}{ Age } \\
\hline$<20$ years & 1 & $1.7 \%$ \\
\hline $21-30$ years & 49 & $81.7 \%$ \\
\hline $31-40$ years & 8 & $13.3 \%$ \\
\hline$>40$ years & 2 & $3.3 \%$ \\
\hline \multicolumn{3}{|l|}{ Gender } \\
\hline Male & 9 & $15 \%$ \\
\hline Female & 51 & $85 \%$ \\
\hline \multicolumn{3}{|l|}{ Marital status } \\
\hline Single & 28 & $46.7 \%$ \\
\hline Married & 32 & $53.3 \%$ \\
\hline \multicolumn{3}{|l|}{ Educational level } \\
\hline Bachelor Degree in Nursing & 22 & $36.7 \%$ \\
\hline Technical Institute of Nursing & 15 & $25 \%$ \\
\hline Secondary Nursing School & 23 & $38.3 \%$ \\
\hline \multicolumn{3}{|l|}{ Years of work experience in ICU } \\
\hline$<2$ years & 20 & $33.3 \%$ \\
\hline $2-5$ years & 6 & $10 \%$ \\
\hline $6-10$ years & 10 & $16.7 \%$ \\
\hline$>10$ years & 24 & $40 \%$ \\
\hline \multicolumn{3}{|c|}{ Attendance of training programs/workshops regarding nasogastric feeding } \\
\hline No & 56 & $93.3 \%$ \\
\hline
\end{tabular}


Data are presented as numbers $(\mathrm{N})$ and frequencies $(\%)$

Table 2 describes the participants' total mean knowledge scores throughout the phases of the study. It showed highly statistically significant differences $(P=$ 0.001 ) between the three knowledge scores throughout the study phases (after 1 month $>$ after 3 months $>$ pre the educational interventions).

Table 2 Total Mean Knowledge Scores of Participant Nurses Throughout the Phases of the Study

\begin{tabular}{|l|c|c|c|}
\hline & Before education & After 1 month & After 3 months \\
\hline Mean \pm SD & $19.5 \pm 2.8$ & $25.3 \pm 2.1$ & $23.9 \pm 2.1$ \\
\hline Pairwise comparison & $\mathrm{A}$ & $\mathrm{B}$ & $\mathrm{C}$ \\
\hline $\mathrm{F}$ & 121.988 & \\
P-value & $<0.001$ & \\
Partial Eta squared & 0.674 & \\
\hline \hline
\end{tabular}

F: Fisher Snedecor Distribution $\mathrm{P} \leq 0.05$ Partial Eta Squared: a measure of effect size $\square$ : mean, SD: standard deviation

Comparisons of column proportions are presented as capital letters $(\mathrm{A}, \mathrm{B}, \mathrm{C}$ : Similar letters $=$ no significant difference and Different letters $=$ significant difference) .

Table 3Participant Nurses' General Knowledge About Nasogastric Feeding Throughout the Phases of the Study

\begin{tabular}{|c|c|c|c|}
\hline \multirow{2}{*}{ NGT Feeding } & \multicolumn{3}{|c|}{ Frequency and Percentage (N=60) } \\
\cline { 2 - 4 } & Before education & After 1 month & After 3 months \\
\hline Definition & $60(100 \%) \mathrm{A}$ & $60(100 \%) \mathrm{A}$ & $60(100 \%) \mathrm{A}$ \\
\hline Indications & $58(96.6 \%) \mathrm{A}$ & $60(100 \%) \mathrm{A}$ & $60(100 \%) \mathrm{A}$ \\
\hline Benefits & $60(100 \%) \mathrm{A}$ & $60(100 \%) \mathrm{A}$ & $60(100 \%) \mathrm{A}$ \\
\hline Contraindication & $58(96.6 \%) \mathrm{A}$ & $60(100 \%) \mathrm{A}$ & $60(100 \%) \mathrm{A}$ \\
\hline
\end{tabular}

Table 4 illustrated statistically significant differences $(\mathrm{P}=<0.0005)$ in nurses' knowledge about the patient's preparation and NGT insertion no statistically significant differences in all items of nurses' knowledge regarding NGT feeding general information throughout the phases of the study as the pairwise comparison showed similar letters.

Table 4Participant Nurses' Knowledge About NGT Insertion Throughout the Phases of the Study

\begin{tabular}{|c|c|c|c|c|}
\hline \multirow{2}{*}{$\begin{array}{c}\begin{array}{c}\text { Steps of NGT insertion } \\
\text { procedure }\end{array} \\
\end{array}$} & \multicolumn{3}{|c|}{ Frequency and Percentage $(\mathrm{N}=60)$} & \multirow[t]{2}{*}{$P$-value } \\
\hline & Before education & After 1 month & After 3 months & \\
\hline \multicolumn{5}{|l|}{ Preparation } \\
\hline Prepare the patient & $\begin{array}{c}29(48.3 \%) \\
\text { A }\end{array}$ & $\begin{array}{c}53(88.3 \%) \\
B\end{array}$ & $\begin{array}{c}44(73.3 \%) \\
C\end{array}$ & $<0.0005$ \\
\hline Prepare equipment & $\begin{array}{c}59(98.3 \%) \\
\text { A }\end{array}$ & $\begin{array}{c}60(100 \%) \\
\mathrm{A}\end{array}$ & $\begin{array}{c}60(100 \%) \\
\mathrm{A}\end{array}$ & --------- \\
\hline \multicolumn{5}{|l|}{ Implementation } \\
\hline $\begin{array}{l}\text { Nursing care when resistance } \\
\text { occurs during NGT insertion }\end{array}$ & $\begin{array}{c}5(8.3 \%) \\
A\end{array}$ & $\begin{array}{c}51(85 \%) \\
B \\
\end{array}$ & $\begin{array}{c}26(43.3 \%) \\
C\end{array}$ & $<0.0005$ \\
\hline
\end{tabular}


According to table 5, statistically significant differences $(p=<0.0005)$ were noted in nurses' knowledge pre and postimplementation of the educational interventions (one month and 3 months) regarding the preparation and implementation of feeding, checking the

Table 5Participant Nurses' Knowledge About NGT Feeding Procedure Throughout the Phases of the Study

\begin{tabular}{|c|c|c|c|c|}
\hline \multirow[t]{2}{*}{ Steps of NGT feeding procedure } & \multicolumn{3}{|c|}{ Frequency and Percentage $(\mathrm{N}=60)$} & \multirow[b]{2}{*}{$P$-value } \\
\hline & $\begin{array}{c}\text { Before } \\
\text { education }\end{array}$ & $\begin{array}{c}\text { After } 1 \\
\text { month }\end{array}$ & $\begin{array}{l}\text { After } 3 \\
\text { months }\end{array}$ & \\
\hline \multicolumn{5}{|l|}{ Assessment } \\
\hline $\begin{array}{l}\text { Check amount of gastric residual volume } \\
\text { (GRV) }\end{array}$ & $\begin{array}{l}49(81.7 \%) \\
\text { A }\end{array}$ & $\begin{array}{l}59(98.3 \%) \\
\text { A }\end{array}$ & $\begin{array}{l}59(98.3 \%) \\
\text { A }\end{array}$ & $\begin{array}{l}------- \\
\end{array}$ \\
\hline \multicolumn{5}{|l|}{ Preparation } \\
\hline Prepare the formula & $\begin{array}{c}26(43.3 \%) \\
\text { A }\end{array}$ & $\begin{array}{c}58(96.7 \%) \\
B\end{array}$ & $\begin{array}{c}58(96.7 \%) \\
B\end{array}$ & $<0.0005$ \\
\hline Elevate HOB $30-45^{\circ}$ & $\begin{array}{c}44(73.3 \%) \\
\text { A }\end{array}$ & $\begin{array}{c}60(100 \%) \\
\mathrm{B}\end{array}$ & $\begin{array}{c}60(100 \%) \\
\mathrm{B}\end{array}$ & $<0.0005$ \\
\hline \multicolumn{5}{|l|}{ Implementation } \\
\hline Time to initiate feeding & $\begin{array}{c}41(68.3 \%) \\
\text { A }\end{array}$ & $\begin{array}{c}60(100 \%) \\
B\end{array}$ & $\begin{array}{c}60(100 \%) \\
B\end{array}$ & $<0.0005$ \\
\hline Hold feeding if GRV $\geq 500$ & $\begin{array}{c}38(63.3 \%) \\
\mathrm{A}\end{array}$ & $\begin{array}{c}60(100 \%) \\
\mathrm{B}\end{array}$ & $\begin{array}{c}60(100 \%) \\
\mathrm{B}\end{array}$ & $<0.0005$ \\
\hline Give medication via NGT & $\begin{array}{c}41(68.3 \%) \\
\mathrm{A}\end{array}$ & $\begin{array}{c}59(98.3 \%) \\
\mathrm{B}\end{array}$ & $\begin{array}{l}59(98.3 \%) \\
\mathrm{B}\end{array}$ & $<0.0005$ \\
\hline \multicolumn{5}{|l|}{ Post NGT feeding care } \\
\hline Check the placement of NGT & $\begin{array}{c}31(51.7 \%) \\
\mathrm{A}\end{array}$ & $\begin{array}{c}57(95 \%) \\
B\end{array}$ & $\begin{array}{c}57(95 \%) \\
\mathrm{B}\end{array}$ & $<0.0005$ \\
\hline $\begin{array}{l}\text { Keep the patient in sitting position after } \\
\text { feeding }\end{array}$ & $\begin{array}{c}51(85 \%) \\
\mathrm{A}\end{array}$ & $\begin{array}{c}60(100 \%) \\
\mathrm{A}\end{array}$ & $\begin{array}{c}60(100 \%) \\
\mathrm{A}\end{array}$ & -------- \\
\hline Nasal and mouth care & $\begin{array}{c}15(25 \%) \\
\mathrm{A}\end{array}$ & $\begin{array}{c}45(75 \%) \\
B\end{array}$ & $\begin{array}{c}45(75 \%) \\
B\end{array}$ & $<0.0005$ \\
\hline $\begin{array}{l}\text { Participant Nurses' Performance of } \\
\text { NGT Feeding } \\
\text { Table } \mathbf{6} \text { showed statistic } \\
\text { significant differences in nurses' t }\end{array}$ & \multicolumn{4}{|c|}{$\begin{array}{l}\text { mean performance scores }(\mathrm{P}=0.001) \\
\text { throughout the three phases of the study } \\
\text { (after } 1 \text { month }>\text { after } 3 \text { months }>\text { pre the } \\
\text { educational interventions). }\end{array}$} \\
\hline
\end{tabular}

Table 6 Total Mean Performance Scores of Participant Nurses throughout the Phases of the Study

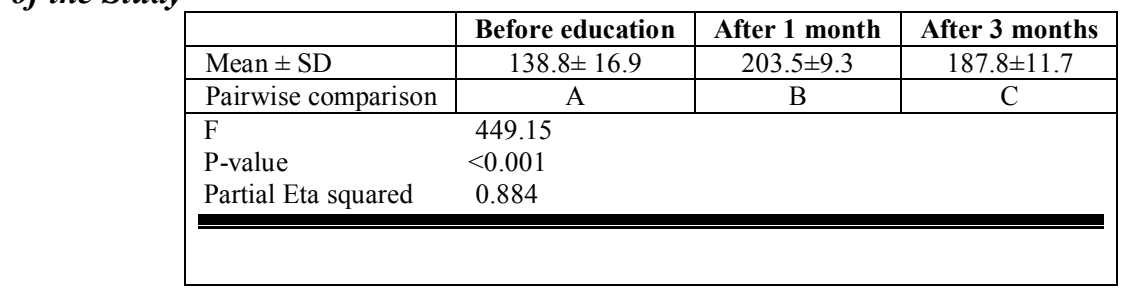

placement of NGT, and nasal and mouth care post-feeding. However, there were no statically significant differences in nurses' knowledge concerning checking the amount of residual volume or positioning after feeding. 
Table 7 showed statistically significant differences in nurses' assessment of patient's daily urine, glucose, acetone, and albumin, and preparation for NGT insertion after one and three months of the training $(\mathrm{P}=<0.0005)$. A significant difference was also noted in nurses' performance of

Table 7Participant Nurses' Performance of NGT Insertion Throughout the Phases of the Study

\begin{tabular}{|c|c|c|c|c|}
\hline \multirow[t]{2}{*}{ NGT insertion section } & \multicolumn{3}{|c|}{ Frequency and Percentage $(\mathrm{N}=60)$} & \multirow[t]{2}{*}{$P$-value } \\
\hline & $\begin{array}{c}\text { Before } \\
\text { education }\end{array}$ & After 1 month & $\begin{array}{l}\text { After 3 } \\
\text { months }\end{array}$ & \\
\hline \multicolumn{5}{|l|}{ Assessment } \\
\hline Assess abdominal bowel sound & $57(95 \%) \mathrm{A}$ & $60(100 \%) \mathrm{A}$ & $60(100 \%) \mathrm{A}$ & ------ \\
\hline Assess the patency of nostrils & $0(0 \%) \mathrm{A}$ & $55(91.7 \%) \mathrm{B}$ & $26(43.3 \%) \mathrm{C}$ & $<0.0005$ \\
\hline $\begin{array}{l}\text { Assess patient's daily for urine, glucose, } \\
\text { acetone, and albumin. }\end{array}$ & $0(0 \%) \mathrm{A}$ & $59(98.3 \%) \mathrm{B}$ & $59(98.3 \%) \mathrm{B}$ & $<0.0005$ \\
\hline \multicolumn{5}{|l|}{ Preparation } \\
\hline Wash hands & $7(11.7 \%) \mathrm{A}$ & $60(100 \%) \mathrm{B}$ & $60(100 \%) \mathrm{B}$ & $<0.0005$ \\
\hline Maintain privacy & $1(1.7 \%) \mathrm{A}$ & $60(100 \%) \mathrm{B}$ & $60(100 \%) \mathrm{B}$ & $<0.0005$ \\
\hline \multicolumn{5}{|l|}{ Implementation } \\
\hline Estimate the proper length of the tube & $\begin{array}{c}58(96.7 \%) \\
\mathrm{A}\end{array}$ & $60(100 \%) \mathrm{A}$ & $60(100) \mathrm{A}$ & ------- \\
\hline Position curved edge of the tube downward & $\begin{array}{c}60(100 \%) \\
\mathrm{A}\end{array}$ & $60(100 \%) \mathrm{A}$ & $60(100 \%) \mathrm{A}$ & $\begin{array}{ll}------ \\
\end{array}$ \\
\hline Insert NGT gently & $\begin{array}{c}60(100 \%) \\
\mathrm{A}\end{array}$ & $60(100 \%) \mathrm{A}$ & $60(100 \%) \mathrm{A}$ & ------ \\
\hline \multicolumn{5}{|l|}{ Post NGT insertion care } \\
\hline Perform nasal care & $7(11.7 \%) \mathrm{A}$ & $55(91.7 \%) \mathrm{B}$ & $22(36.7 \%) \mathrm{C}$ & $<0.0005$ \\
\hline Document time of NGT insertion & $\begin{array}{c}11(18.3 \%) \\
\mathrm{A}\end{array}$ & $60(100 \%) \mathrm{B}$ & $24(40 \%) \mathrm{C}$ & $<0.0005$ \\
\hline
\end{tabular}

According to table 8, there were statistically significant differences $(\mathrm{P}=<0.0005)$ in nurses' performance of NGT feeding one month after the training as the practice was improved. However, nurses' performance of some steps was declined after three months, such as checking the NGT placement, giving the prescribed formula, and flushing the NGT. No statistically significant differences were noted concerning checking the GRV or post-insertion care as the practice improved one month after the training but declined 3 months post-training $(\mathrm{P}=<0.0005)$. However, no statistically significant differences were detected in nurses' assessment of abdominal bowel sound or the insertion of the NGT.

$\mathrm{A}$

positioning the patient as preparation for feeding throughout the three phases of the study.

Statistically significant differences $(\mathrm{P}=<0.0005)$ were also noted regarding nurses' documentation of the time of checking GRV, giving medication, and any untoward problems. However, no significant differences were observed in nurses' documentation of the time of feeding during the three phases of the study 
Inayat F.Elsayed*1, Amal R. Reyad2et. al.

Table 8Participant Nurses' Performance of NGT Feeding Throughout the Phases of the Study

\begin{tabular}{|c|c|c|c|c|}
\hline \multirow[t]{2}{*}{ NGT feeding domains } & \multicolumn{3}{|c|}{ Frequency and Percentage $(\mathrm{N}=60)$} & \multirow[t]{2}{*}{$P$-value } \\
\hline & Before training & After 1 month & After 3 months & \\
\hline \multicolumn{5}{|l|}{ Assessment } \\
\hline Check NGT placement & $6(10 \%) \mathrm{A}$ & $59(98.3 \%) \mathrm{B}$ & $22(36.7 \%) \mathrm{C}$ & $<0.0005$ \\
\hline Check GRV & $54(90 \%) \mathrm{A}$ & $57(95 \%) \mathrm{A}$ & $57(95 \%) \mathrm{A}$ & ------- \\
\hline Assess bowel sounds & $10(16.7 \%) \mathrm{A}$ & $55(91.7 \%) \mathrm{B}$ & $55(91.7 \%) \mathrm{B}$ & $<0.0005$ \\
\hline \multicolumn{5}{|l|}{ Preparation } \\
\hline Explain the procedure to patient & $6(10 \%) \mathrm{A}$ & $60(100 \%) \mathrm{B}$ & $60(100 \%) \mathrm{B}$ & $<0.0005$ \\
\hline Maintain patient's privacy & $10(16.7 \%) \mathrm{A}$ & $60(100 \%) \mathrm{B}$ & $60(100 \%) \mathrm{B}$ & $<0.0005$ \\
\hline Put the patient in sitting position & $56(93.3 \%) \mathrm{A}$ & $55(91.7 \%) \mathrm{A}$ & $55(91.7 \%) \mathrm{A}$ & ------ \\
\hline \multicolumn{5}{|l|}{ Implementation } \\
\hline Give the prescribed formula & $4(6.7 \%) \mathrm{A}$ & $57(95 \%) \mathrm{B}$ & $26(43.3 \%) \mathrm{C}$ & $<0.0005$ \\
\hline Flush NGT with 20-30 ml water & $2(3.3 \%) \mathrm{A}$ & $56(93.3 \%) \mathrm{B}$ & $26(43.3 \%) \mathrm{C}$ & $<0.0005$ \\
\hline Hold NGT feeding if GRVs $>500 \mathrm{ml}$ & $40(66.3 \%) \mathrm{A}$ & $59(98.3 \%) \mathrm{B}$ & $59(98.3 \%) \mathrm{B}$ & $<0.0005$ \\
\hline \multicolumn{5}{|l|}{ Post feeding care } \\
\hline $\begin{array}{l}\text { Elevated HOB at } 30-45 \text { degree for } 30 \\
\text { min }\end{array}$ & $34(56.7 \%) \mathrm{A}$ & $60(100 \%) \mathrm{B}$ & $60(100 \%) \mathrm{B}$ & $<0.0005$ \\
\hline Provide oral hygiene every $2-4$ hours & $1(1.7 \%) \mathrm{A}$ & $50(83.3 \%) \mathrm{B}$ & $50(83.3 \%) \mathrm{B}$ & $<0.0005$ \\
\hline \multicolumn{5}{|l|}{ Documentation } \\
\hline Time of feeding & $60(100 \%) \mathrm{A}$ & $60(100 \%) \mathrm{A}$ & $60(100 \%) \mathrm{A}$ & -------- \\
\hline Time to check GRVs & $8(13.3 \%) \mathrm{A}$ & $53(88.3 \%) \mathrm{B}$ & $53(88.3 \%) \mathrm{B}$ & $<0.0005$ \\
\hline Time to give medication via NGT & $18(30 \%) \mathrm{A}$ & $58(96.7 \%) \mathrm{B}$ & $58(96.7 \%) \mathrm{B}$ & $<0.0005$ \\
\hline Any problem arises & $7(11.7 \%) \mathrm{A}$ & $53(88.3 \%) \mathrm{B}$ & $60(100 \%) \mathrm{B}$ & $<0.0005$ \\
\hline
\end{tabular}

primary ones responsible for the delivery of NGT feeding for critically ill patients. Hence, their knowledge and practice are significant for ensuring the delivery of adequate nutritional support for their patients. This study aimed to assess the effect of NGT feeding educational interventions on critical care nurses' knowledge and performance. The study involved a sample of sixty participant nurses. Most of them were young females and their ages ranged from 21 to 30 years. Despite the increasing number of males who select nursing as a career, yet nursing continues to be a female dominant profession in Egypt. The young age of the participants could be due to the appointment of novice critical care nurses in the selected ICUs. This finding is consistent with other similar studies which illustrated that the majority of the participant nurses were less than
Regarding nurses' qualifications, more than one-third of the participant nurses were holding a Bachelor's degree in nursing and had more than 10 years of work experience in the ICU. This is an interesting finding because there is a national trend in Egypt to appoint graduates of Faculties of Nursing in ICUs to enhance the quality of care provided for critically ill patients (Mohamed, Kandeel, Abosaeda \& Ali, 2020). An investigation was conducted by Bedier et al. (2016) to assess the effect of the educational program on nurses' practice regarding caring for patients undergoing NGT feeding and reported that only $10 \%$ of the nurses had a Bachelor's degree in nursing. However, Özbaş and Baykara (2018) found that $55.8 \%$ of the nurses had a Bachelor's or Master's degree. Another study conducted by Morphet et al. (2016) to 
explore Australian nurses' enteral nutrition knowledge and sources of information reported that most of the participants had completed a postgraduate qualification. This could be because continuous professional education for nurses is encouraged and supported in western countries.

The current study illustrated that the vast majority of the participants didn't attend any training programs or workshops related to NGT feeding. This could be attributed to the unavailability of regulations or policies to commit nurses to attend continuous in-service training programs to update their knowledge and skills. This finding supports the results of other studies which emphasized the importance of training programs in improving nurses' knowledge and practice, and consequently enhancing the quality of nursing care in ICUs (Ahmed \& Mondal, 2014; F.Ahmed, Ahmed, Albitar, Ghoneim, 2018; Bedier, et al., 2016; ElMeanawi, 2017).

The findings of the current study showed a significant improvement in nurses' total mean knowledge and performance scores regarding NGT feeding one month following the educational interventions. These findings are harmonious with other investigations that implemented NGT educational programs in Egyptian hospitals and reported a significant enhancement in the participants' knowledge and practice post the training program (Ahmed, et al., 2018; Bedier, et al., 2016; El-Meanawi, 2017; Mohammed \& Abdel Fattah, 2018; Shahin, et al., 2012).

Our results are also supported by other recent international studies. In Taiwan, Chang et al. (2015) implemented a systematic nursing educational intervention about NGT feeding on 106 caregivers (experimental group) and provided routine education (educational pamphlet) to 127 caregivers (control group). Then the effect on caregivers and the incidence of feeding complications among patients were evaluated. The authors reported higher post-test knowledge and skills among the experimental group. In South Korea, Kim and Chang (2019) implemented an EF educational program on 205 nurses from nine ICUs in four hospitals. They illustrated that the participants' perception, knowledge, and practice around enteral nutrition meaningfully improved following the program. In Saudi Arabia, Bomozah (2020) highlighted the effectiveness of the NGT feeding educational interventions in enhancing the knowledge and performance of the studied nurses.

The findings of the current study exhibited that nurses' total mean knowledge and performance scores were declined 3 months after the educational interventions but it was better than preeducation scores. In general, retaining nurses' knowledge and performance within 3 to 6 months after training programs is well documented in the literature. Bedier, et al. (2016) reported significant improvement in the total scores of nurses' practices regarding caring of patients undergoing NGT feeding which declined 3 months and 6 months post the educational program. Similarly, Ragheb, N. El Sayed, El Sayed, and Metwally (2016) studied the effect of a training program on reducing nurses' medication errors in the ICU and noted enhancement in nurses' knowledge immediately after the program and a decline in their knowledge three months later. In light of these findings, NGT feeding refreshers are recommended for critical care nurses to keep them updated and competent. 


\section{Limitations}

The study was conducted on a small group of critical care nurses from four ICUs in one hospital which limits the generalizability of the research findings. Furthermore, there were difficulties in following the educational interventions plan schedule due to participant nurses' heavy work in the ICU.

\section{Conclusion and Recommendations}

The study concludes that educational interventions are a useful strategy to improve critical care nurses' knowledge and performance of NGT feeding for critically ill patients. This study highlights the need for continuous in-service training programs for critical care nurses to keep them up-to-date and skilled. It is also important to evaluate nurses' performance of NGT feeding periodically to ensure that they follow the evidence-based practice. Future investigations are necessary to evaluate the effectiveness of NGT educational interventions on critically ill patients' clinical outcomes.

\section{Acknowledgment}

The authors would like to thank the critical care nurses who accepted to take part in this study.

\section{Declaration of Conflicting Interests}

The authors declared no potential conflicts of interest concerning the research, authorship, and/or publication of this article.

\section{References}

Abdullah, M., Mohammed, W., \& Ismail, M. (2014). Nurses' knowledge and practices about administration of medications via nasogastric tube among critically ill patients. Journal of Education and Practice, 5(1), 147-159.

Ahamed, N., \& Mondal, D. (2014). Assessment of knowledge and practice of staff nurses regarding ryle's tube feeding in a selected hospital of kolkata, west bengal. SMU Medical Journal, 1(2), 294302.

Ahmed, F., Ahmed, O., Albitar, E., Ghoneim, S. (2018). Effect of educational nursing guidelines regarding enteral feeding on nurses' knowledge and practices at critical care units. IOSR Journal of Nursing and Health Science, 7(5), 69-75.DOI: 0705026975

Al Kalaldeh, M., Watson, R., \& Hayter, M. (2015). Jordanian nurses' knowledge and responsibility for enteral nutrition in the critically ill. British Association of Critical Care Nurses, Nursing in Critical Care, 20(5), 229-241.Retrieved from: https://doi.org/10.1111/nicc.12065

Al-Hawaly, M., Ibrahim, M. H., \& Qalawa, S. A. (2016). Assessment of nurses' knowledge and performance regarding feeding patients with nasogastric tube in Ismailia General Hospital. Med $J$ Cairo Univ, 84, 99-105.

Babapour, S. K., Esmaeili, R., Esteki, T., Naderiravesh, N., Pourhoseingholi, M. A., \& Marzangu, S. M. H. (2016). Nurses' practice about performance of nasogastric tube feeding in intensive care unit. International Journal of Advanced Biotechnology and Research, 7, 1585-1594. Retrieved from: http://www.bipublication.com

Barker, L. A., Gout, B. S., \& Crowe, T. C. (2011). Hospital malnutrition: prevalence, identification and impact on patients and the healthcare system. 
The Effect of Nasogastric Tube etc...

International Journal of Environmental Research and Public Health, 8(2), 514527.DOI:10.3390/ijerph8020514

Bear, D., Wandrag, L., Merriweather, J., Connolly, B., Hart, N., \& Grocott M. (2017). The role of nutritional support in the physical and functional recovery of critically ill patients: a narrative review. Critical Care, 21, 226236. Retrieved from: https://doi.org/10.1186/s13054017-1810-2

Bedier, N. A., EL-Ata, A. B. A., \& Shehab, M. S. (2016). Effect of educational program on nurses' practice related to care of patients undergoing nasogastric tube feeding. International Journal of Caring Sciences, 9(2), 432. Retrieved from: www.internationaljournalofcarings ciences.org

Bennett, K. A., Robertson, L. C., \& AlHaddad, M. (2016). Recognizing the critically ill patient. Anaesthesia \& Intensive Care Medicine, 17(1), 1-4. Retrieved from:

https://doi.org/10.1016/j.mpaic.20 15.10 .001

Bomozah, E. A. (2020). Effect of nasogastric tube feeding care program on nurse' knowledge

and practice. International Journal of Novel Research in Healthcare and Nursing,

7(2), 633-653.

Bourgault, A. M., Ipe, L., Weaver, J., Swartz, S., \& O’Dea, P. J. (2007). Development of evidence-based guidelines and critical care nurses' knowledge of enteral feeding. Critical Care Nurse, 27(4), 17-29. Retrieved from: https://doi.org/10.4037/ccn2007.27 .4 .17

Chang, S. C., Huang, C. Y., Lin, C. H., Tu, S. L., Chao, M. S., \& Chen, M. H. (2015). The effects of systematic educational interventions about nasogastric tube feeding on caregivers' knowledge and skills and the incidence of feeding complications. Journal of Clinical Nursing, 24(11-12), 1567-1575. Retrieved from: https://doi.org/10.1111/jocn.12748

Correia, M. I. T., \& Waitzberg, D. L. (2003). The impact of malnutrition on morbidity, mortality, length of hospital stay and costs evaluated through a multivariate model analysis. Clinical nutrition, 22(3), 235-239.DOI: $\quad 10.1016 / \mathrm{s} 0261$ 5614(02)00215-7.

Das, S., Patra, D., \& Pradhan, P. (2015). Critical care nurses' knowledge and skill regarding enteral nutrition in critically Ill patients at a glance. $J$ Nurs Sci Pract, 4(3), 35-42.

El-Meanawi, N. H. K. K. (2017). Impact of implementing an educational programme regarding care of nasogastric tube feeding on nurses knowledge and performance. IOSR J Nurs Health Serv, 6(1), 101-109. DOI:10.9790/1959-060104101109

Gill, K. (2019). An Exploratory Study to Assess the Knowledge Regarding Enteral Feeding among Staff Nurses in Christian Medical College \& Hospital, Ludhiana, Punjab. International Journal of Nursing Education, 11(2), 114118.DOI: 9357.2019.00053.9 
Kim, H., \& Chang, S. J. (2019). Implementing an educational program to improve critical care nurses' enteral nutritional support. Australian Critical Care, 32(3), 218-222.Retrieved from: https://doi.org/10.1016/j.aucc.2018 .04 .001

Kim, H., \& Choi-Kwon, S. (2011). Changes in nutritional status in ICU patients receiving enteral tube feeding: A prospective descriptive study. Intensive and Critical Care Nursing, 27(4), 194201.Rretrieved from: https://doi.org/10.1016/j.iccn.2011 .05 .002

Kim, H., Stotts, N. A., Froelicher, E. S., Engler, M. M., \& Porter, C. (2012). Why patients in critical care do not receive adequate enteral nutrition? A review of the literature. Journal of Critical Care, 27(6), 702-713.DOI: 10.1016/j.jcrc.2012.07.019.

Kirkland, L. L., Kashiwagi, D. T., Brantley, S., Scheurer, D., \& Varkey, P. (2013). Nutrition in the hospitalized patient. Journal of Hospital Medicine, 8(1), 52-58. Retrieved from: https://doi.org/10.1002/jhm.1969

Kunwar, A., \& Koirala, P. (2019). Nurses' Knowledge and Practice regarding nasogastric

tube feeding at a teaching hospital, Bharatpur. International Journal of Modern Pharmaceutical Research, 3(4), 06-11.

Marshall, A. (2008). Information use in clinical practice: A case study of critical care nurses' enteral feeding decisions. (Doctoral Dissertation, The University of Sydney ).
Marshall, A. P., \& West, S. H. (2006). Enteral feeding in the critically ill: are nursing practices contributing to hypocaloric feeding?. Intensive and Critical Care Nursing, 22(2), 95-105. Retrieved from: https://doi.org/10.1016/j.iccn.2005 .09 .004

McClave S.A., Martindale, R. G. Rice T, W. \& Heyland D. K. (2014). Feeding the critically ill patient. Crit Care Med, 42(12), 26002610.

DOI: 10.1097/CCM.0000000000000654 Metwaly, E., Mohammed, E., \& Mohammed, M. (2013). Nurses' performance regarding nasogastric tube feeding in intensive care units. Zagazig Nursing Journal, 9(1), 69-86.Retrieved from: znj.journals.ekb.eg

Mohammed, A., \& Abdel Fattah, S. (2018). The effect of educational program on nurse's knowledge and practices about nasogastric tube feeding at neonatal intensive care units. Journal of Nursing Education and Practice, 8 (8), 2127.Retrieved from: http://research.asu.edu.eg/handle/1 23456789/169188

Mohamed A. M., Kandeel, N. A., Abosaeda A. I., \& Ali W, G. (2020) Effect of Educational Sessions about Early Mobilization of Critically Ill Patients on Nurses' Knowledge and Practices. IOSR Journal of Nursing and Health Science, 9(5), 01-09.

Mohammed, M., Mahmoud, M., Sleem, H., \& Shehab, M. (2017). Assessment of the nurses performance in providing care to patients undergoing nasogastric tube in suez canal university 
hospital. International Journal of Caring Sciences, 10(2), 915-920.

Morphet, J., Clarke, A. B., \& Bloomer, M. J. (2016). Intensive care nurses' knowledge of enteral nutrition: a descriptive questionnaire. Intensive and critical care nursing, 37, 6874. Retrieved from: https://doi.org/10.1016/j.iccn.2016 .07 .001

Mula, C., Ncama, B. P., \& Maluwa, A. (2014). Nurses' competency and challenges in enteral feeding in the Intensive Care Unit (ICU) and High Dependency Units (HDU) of a referral hospital, Malawi. Malawi Medical Journal, 26(3), 55-59.

Ndahimana, D., \& Kim, E. K. (2018). Energy requirements in critically ill patients. Clinical Nutrition Research, 7(2), 81-90.

Ojo, O., Keaveney, E., Wang, X. H., \& Feng, P. (2019). The effect of enteral tube feeding on patients' health-related quality of life: A systematic review. Nutrients, 11(5),

1046.DOI: $10.3390 / \mathrm{nu} 11051046$

Özbaş, N., \& Baykara, Z. G. (2018). The determination of the level of knowledge of nurses on enteral tube feeding Hemşirelerin tüple enteral beslenme konusunda bilgi düzeylerinin belirlenmesi. Journal of Human Sciences, 15(1), 359367. Retrieved from:jhumansciences.com

Polit, D., \& Beck, C. (2018). Essentials of Nursing Research: Appraising Evidence for Nursing Practice (9th ed.). Philadelphia: Lippincott Williams \& Wilkins.

Preiser, J. C., Ichai, C., Orban, J. C., \& Groeneveld, A. B. J. (2014).
Metabolic response to the stress of critical illness. British Journal of Anaesthesia, 113(6), 945954.DOI: $10.1093 / \mathrm{bja} / \mathrm{aeu} 187$

Ragheb, S. E., El.Sayed, N.M., El.Sayed, S.H., \& Metwally, F. G. (2016). Effect of training program on reduction of nurse's medication errors. Zagazig Nursing Journal, 12(2), 116-133.DOI: 10.21608/znj.2016.39000

Sauer, A. C., Alish, C. J., Strausbaugh, K., West, K., \& Quatrara, B. (2016). Nurses needed: identifying malnutrition in hospitalized older adults. NursingPlus Open, 2, 2125.Retrieved from: https://doi.org/10.1016/j.npls.2016 .05 .001

Shahin, M., Mohamed, W., \& Sayed, M. (2012). Nurses Knowledge and Practices Regarding Enteral Nutrition at the Critical Care Department of Al-Manial University Hospital in Egypt: Impact of a Designed Instructional Program. Journal of American Science, 8(11), 397-404.

Stewart, M. L. (2014). Interruptions in enteral nutrition delivery in critically ill patients and recommendations for clinical practice. Critical Care Nurse, 34(4), 14-22. Retrieved from: https://aacnjournals.org/ccnonline/ article-abstract/34/4/14/20537

van Vliet, I. M., Gomes-Neto, A. W., de Jong, M. F., Jager-Wittenaar, H., \& Navis, G. J.

(2020). High prevalence of malnutrition both on hospital admission and predischarge. Nutrition, 77, 110814. Retrieved from: https://doi.org/10.1016/j.nut.2020. 110814 
Inayat F.Elsayed*1, Amal R. Reyad2et. al.

Williams, T. A., \& Leslie, G. D. (2004). A review of the nursing care of enteral feeding tubes in critically ill adults: part I. Intensive and Critical Care Nursing, 20(6), 330-343.DOI:

10.1016/i.iccn.2004.08.002.

$\mathrm{Xu}$, L. C., Huang, X. J., Lin, B. X., Zheng, J. Y., \& Zhu, H. H. (2020). Clinical nurses' nasogastric feeding practices in adults: a multicenter cross-sectional survey in

China. Journal of International Medical Research,48(4), 113.DOI:

$\underline{10.1177 / 0300060520920051}$ 